Journal of Mechanical Engineering and Sciences

ISSN (Print): 2289-4659; e-ISSN: 2231-8380

Volume 12, Issue 4, pp. 4285-4299, December 2018

(C) Universiti Malaysia Pahang, Malaysia

DOI: https://doi.org/10.15282/jmes.12.4.2018.22.0368

\title{
Multi-pass friction stirred clad welding of dissimilar joined AA6061 aluminium alloy and brass
}

\section{Nora Osman, Zainuddin Sajuri* and Mohd Zaidi Omar}

\author{
Centre for Materials Engineering and Smart Manufacturing (MERCU), \\ Faculty of Engineering \& Built Environment, Universiti Kebangsaan Malaysia, \\ 43600 Bangi, Malaysia. \\ Phone: +603-89118017; Fax: +603-89259659 \\ *Email: zsajuri@ukm.edu.my
}

\begin{abstract}
In the past years, joining of copper and aluminium has attracted much attention to allow the utmost use of the special properties of both the metals. Friction stir welding (FSW) technology is feasible to join dissimilar materials compared to conventional fusion welding methods because of its solid-state nature. The present article provides an extensive insight into dissimilar copper to aluminium materials joined by FSW technology. The effect of overlapping between consecutive passes of FSW on the microstructure and mechanical properties of AA6061-brass was examined. FSW was carried out at three shoulder-overlapping percentages, i.e. 0, 50, and 100, and at a constant rotational speed of $1055 \mathrm{rpm}$ and traverse speeds of $5.5 \mathrm{~mm} / \mathrm{min}$ of the FSW tool. Microstructural analysis was determined by optical microscopy, SEM and XRD while mechanical properties were evaluated by micro-hardness and peel tests. The increase of micro-hardness in all SZ compared to base metal is caused by plastic deformation and dynamic recrystallisation at the same time during the welding process. The microhardness and grain size of SZ for all samples remained approximately constant without variation between passes. Hardness across TMAZ/HAZ of $\mathrm{Al}$ is almost constant and lower than that of the Al-base metal, due to artificially aged precipitation hardened aluminium alloy. The peel results indicated that the 50\% shoulder had the highest peel strength due to shoulder influenced region that increased tool penetration under the constant axial load, producing a better weld quality. In contrast, $0 \%$ overlapping sample has a too low overlapped region that produced low interface strength, resulted in inappropriate metallurgical bonding between the $\mathrm{Al}-\mathrm{Cu}$. Moreover, the sample with too overlapping of $100 \%$ overlapping rises the peak temperature of the overlapped zone due to the pin-preheating effected by the previous pass, which caused grain coarsening, liquation and rearrangement of IMCs, thus produced surface grooves at the Al/Brass interface that lower the peel strength. The XRD results revealed that the multi-spectrum in the $\mathrm{SZ}$ is made up of $\mathrm{CuAl}_{2}, \mathrm{Cu}_{4} \mathrm{Al}_{9}, \mathrm{CuAl}$ and $\mathrm{CuZn}$ intermetallic compounds, which affected the strength of the resulting welds.
\end{abstract}

Keywords: friction stir cladding; dissimilar joining; multi-pass welding; shoulder overlap. 


\section{INTRODUCTION}

Dissimilar metal joining is employed in various applications requiring specific combination(s) of properties in order to reduce cost and materials usage. Many emerging applications in power generation and the chemical, petrochemical, nuclear, aerospace, transportation, and electronics industries increase the incidence/usage of joining of dissimilar materials via methods such as friction welding and friction stir welding [1-3]. Due to the different thermo-mechanical and chemical properties of the materials, the joining of dissimilar materials becomes more challenging than that of similar metals [2].

Copper, in particular, has excellent electric conductivity, but its high-density precludes its application in lightweight designs. Also, the higher market price of copper, especially in the context of using it in microelectronics, lead to its replacement with aluminium, which shares many similarities with copper but is markedly cheaper and less dense [4,5]. The AA6061-T6 aluminium alloy has a high resistance to corrosion, good workability, and excellent joining characteristics [6]. Although the replacement of aluminium with copper is viable, welding it to copper is not a straightforward affair. Joining $\mathrm{Al}-\mathrm{Cu}$ is generally more difficult than that of homogeneous materials due to the different physico-chemical properties of both alloys [2,7-9]. The fusion welding of aluminium and copper is generally formidable due to the wide differences in their physico-chemical and thermo-mechanical properties and its tendency to form brittle intermetallic compounds (IMCs)[8].

Consequently, the solid-state joining methods, such as roll welding, friction welding, and explosive welding is fast gaining traction in research [10]. However, it should also be pointed out that despite their aforementioned benefits, these methods also suffer from a few drawbacks; i.e. friction welding's and roll welding's lack of versatility, and explosive welding, which results in safety problems. This necessitates the proper study of welding of Al-Cu.

An alternate process of joining Al-Cu alloy is friction stir welding (FSW). FSW is known as green technology and important achievement in metal joining in a decade because it does not involve any use of filler metal and without concern for the compatibility of composition (versatility), no cover gas or flux is used (environmentalfriendly) and energy efficiency compared to conventional fusion welding [11]. However, literature is mostly concerned with the butt and single seam lap joint configurations, and only a few studies involved friction stir welding of multiple passes [12-16]. Leal and Loureiro [16] reported friction stir welding of multiple passes on AA5083-O and three overlapping passes with AA6063-T6. Their results showed an increase in weld hardness and strength due to plastic deformation and dynamic recrystallisation in the stirred zone and TMAZ for AA5083-O. The AA6063 exhibited lower hardness and strength values relative to its base metal. The grain size for both alloys in the stirred zone remained consistent between passes for both alloys and defects found along the entire length of pass 1 of AA5083 and was completely reduced by the pass 4 .

Generally, multi-pass welding strategy is to increase the bonding area in the dissimilar friction stir lap welding, especially in the large surface area. Thus, is beneficial to study the effect of multi-pass welding to identify whether the overlap pass is able to enhance the overall joining either by reducing defects or increasing strength. By performing various overlapped welding passes it was possible to analyse the quality of the bonding across the multi-pass weld. Leitao et al. [17] reported that overlapping causes the material to be softened by shoulder influenced area from previous pass and yields to greater tool axial force on the base metal, producing better weld quality. Previous study 
by Lakhsminarayanan and Annamalai [15] indicated that $50 \%$ overlap ratio yielded superior bond and shear strength compared with its counterparts due to the exposure of previously stirred material to the current pass that creates shoulder influenced region. Therefore, in this paper, the effects of performing multi-pass friction clad welding for dissimilar $\mathrm{Al}-\mathrm{Cu}$ join sheets are elucidated. The mechanical and microstructural properties of the resultant welds are also analysed and discussed.

\section{METHODS AND MATERIALS}

Al6061 aluminium alloy and brass were used as the top and bottom sheet of the clad joints, respectively. The nominal composition in terms of weight per cent for both alloys and their thermo-mechanical and physico-chemical properties is tabulated in Table 1 and 2. The grade of the brass used contains 60 per cent copper and 40 per cent zinc. Both metals were annealed and are $1.5 \mathrm{~mm}$ thick. The sheets were cut and machined into rectangular welding samples, measuring $150 \mathrm{~mm}$ in length and $150 \mathrm{~mm}$ wide, which were clad-welded using a conventional milling machine. Prior to welding, the surface of the plates was ground using fine emery papers to remove the oxide film, and subsequently cleaned with ethanol. The Al alloy sheet was overlaid on a brass plate and clamped onto an anvil. Previous research reported better weld quality when the welding tool was plunged into the softer material [18]. The schematic diagram of the material, tool and welding process is illustrated in Figure 1.

Figure 2 shows the welding tool used in the FSW process. It is made of hardened D2 tool steel alloy, with a concave shoulder measuring $14 \mathrm{~mm}$ in diameter and a threaded cylindrical pin with a diameter and length of $4 \mathrm{~mm}$ and $2 \mathrm{~mm}$. The welding process parameters are tabulated in Table 3 . The tilt angle of the rotating tool was 3 degrees with respect to the z-axis of the milling machine for all of the specimens. The welding was conducted via FSW at tool rotational speeds of $1055 \mathrm{rpm}$ and traverse speeds of 5.5 $\mathrm{mm} / \mathrm{min}$. Welds were made in two passes ( $0 \%$ shoulder overlap), three passes $(50 \%$ shoulder overlap), and four passes (100\% shoulder overlap). When double-pass welds were made, both passes were created using similar tools and welding parameters. The tool rotation, welding direction, penetration depth of $2.2 \mathrm{~mm}$ and top sheet were kept constant.

For metallographic analyses, the specimens were prepared using procedures outlined in ASTM E3-01. The aluminium alloy was over-etched using modified Keller's reagent $\left(2 \mathrm{~mL} \mathrm{HF}, 3 \mathrm{~mL} \mathrm{HCl}, 5 \mathrm{~mL} \mathrm{HNO}_{3}\right.$, and $\left.90 \mathrm{~mL} \mathrm{H}_{2} \mathrm{O}\right)$ to reveal its grains so that it can be imaged using a tabletop SEM. The brass was etched using a solution of $10 \mathrm{~g} \mathrm{FeCl}_{3}$, $30 \mathrm{ml} \mathrm{HCl}$, and $85 \mathrm{ml} \mathrm{H}_{2} \mathrm{O}$, while an optical microscope was used to image the microstructure of the welds. The phases detected in the cross-sections of Al-brass weld was analysed using a D8 Advance 9 Position diffractometer (Bruker AXS Germany) $\mathrm{XRD}$ at $40 \mathrm{kV}$ and $\mathrm{Cu} \mathrm{K}-\alpha 1$ radiation. The diffraction data were collected over a $2 \mathrm{~h}$ range of $5-100 \mathrm{deg}$. The phases were identified using the Eva software.

The peel test was used to estimate the strength of the welded specimen. All of the tests were conducted on Zwick $100 \mathrm{kN}$ testing machine at a constant cross-head displacement rate of $50 \mathrm{~mm} / \mathrm{min}$. The schematic view of the peel specimen is according to Figure 3. The failure loads were recorded for each specimen. Furthermore, the microhardness of the welded samples was measured at different points along the welded zone and through-thickness using a Vickers micro-hardness tester. For this purpose, a load of $100 \mathrm{~g}$ was applied for 15 seconds. 
Table 1. Chemical composition of the welded materials.

\begin{tabular}{c|lllllllllll}
\hline \multicolumn{10}{c}{ Chemical composition [wt \%] } \\
\hline Alloys & $\mathrm{Al}$ & $\mathrm{Mg}$ & $\mathrm{Si}$ & $\mathrm{Cu}$ & $\mathrm{Zn}$ & $\mathrm{Fe}$ & $\mathrm{S}$ & $\mathrm{Cl}$ & $\mathrm{Cr}$ & $\mathrm{Na}$ & $\mathrm{Ni}$ \\
\hline AA6061 & 97.19 & 1.00 & 0.91 & 0.30 & 0.02 & 0.21 & 0.11 & 0.09 & 0.08 & 0.07 & 0.01 \\
Brass & 0.00 & 0.00 & 0.00 & 60.20 & 39.80 & 0.00 & 0.00 & 0.00 & 0.00 & 0.00 & 0.00 \\
\hline
\end{tabular}

Table 2. Thermo-mechanical and physico-chemical properties of AA6061 aluminum and Brass [19]

\begin{tabular}{lcc}
\hline Thermal Properties & Brass & Aluminum \\
\hline Coefficient of & $20.8 \mu \mathrm{m} / \mathrm{m}-{ }^{\circ} \mathrm{C}$ & $25.2 \mu \mathrm{m} / \mathrm{m}-{ }^{\circ} \mathrm{C}$ \\
Thermal Expansion & $@$ Temperature $20.0-300{ }^{\circ} \mathrm{C}$ & $@$ Temperature $20.0-300{ }^{\circ} \mathrm{C}$ \\
(CTE), linear & $0.375 \mathrm{~J} / \mathrm{g}-{ }^{\circ} \mathrm{C}$ & $0.896 \mathrm{~J} / \mathrm{g}-{ }^{\circ} \mathrm{C}$ \\
Specific Heat & & \\
Capacity & $123 \mathrm{~W} / \mathrm{m}-\mathrm{K}$ & $180 \mathrm{~W} / \mathrm{m}-\mathrm{K}$ \\
Thermal & $@$ Temperature $20.0{ }^{\circ} \mathrm{C}$ & \\
Conductivity & $900-905^{\circ} \mathrm{C}$ & $582-651.7{ }^{\circ} \mathrm{C}$ \\
Melting Point & $900{ }^{\circ} \mathrm{C}$ & $582{ }^{\circ} \mathrm{C}$ \\
Solidus & $905{ }^{\circ} \mathrm{C}$ & $651.7{ }^{\circ} \mathrm{C}$ \\
Liquidus & &
\end{tabular}

(a)

$0 \%$ shoulder overlap

(b)

$50 \%$ shoulder overlap

(c)

$100 \%$ shoulder overlap
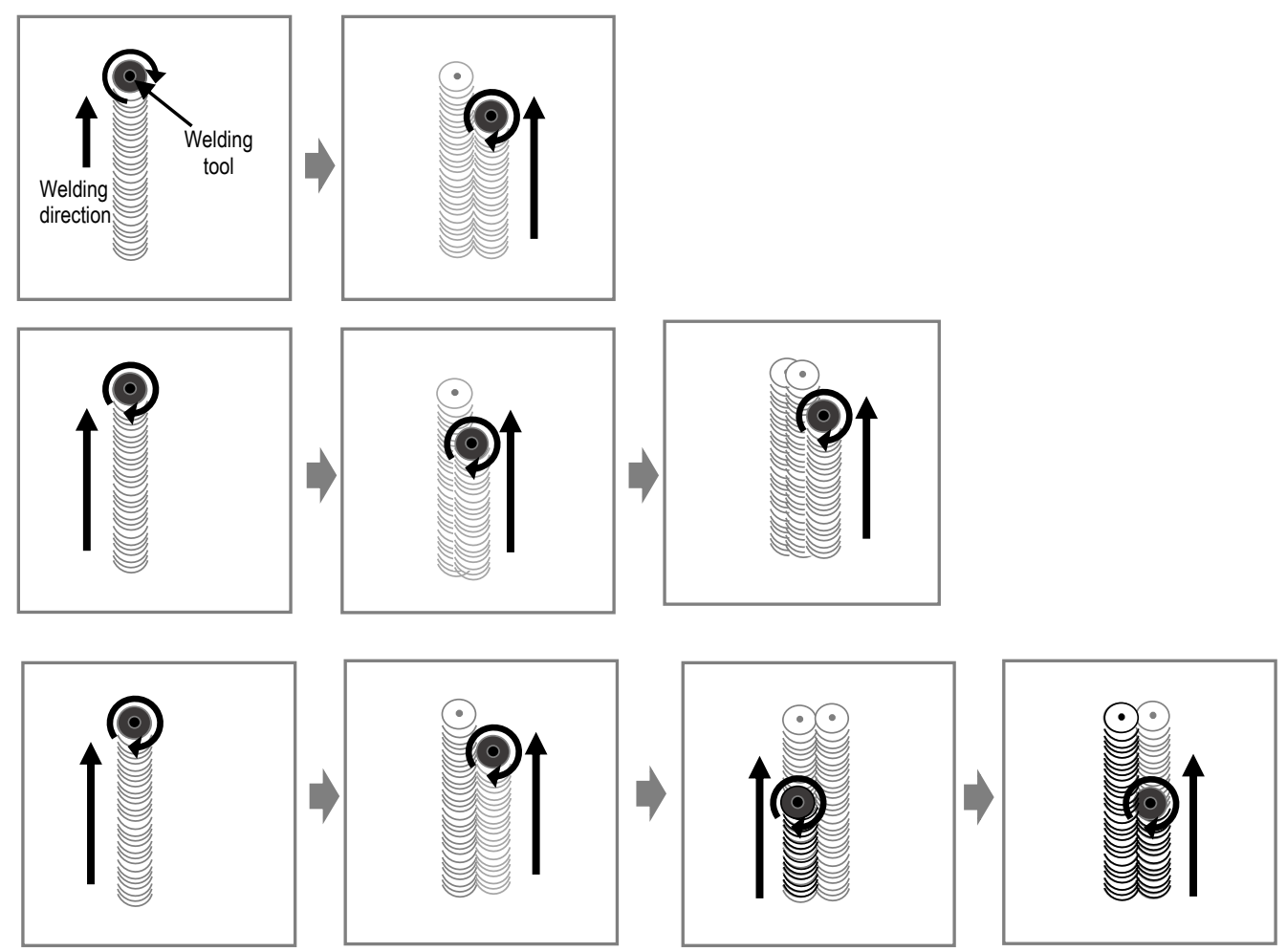

Figure 1. Schematic diagram of the material, tool and welding process for; (a) 0, (b) 50 and (c) $100 \%$ shoulder overlap. 
Table 3. Welding parameters used in this study

\begin{tabular}{lc}
\hline \multicolumn{1}{c}{ Parameter } & Values \\
\hline Welding Speed $(\mathrm{mm} / \mathrm{min})$ & 5.5 \\
Rotational Speed $(\mathrm{rpm})$ & 1055 \\
Shoulder overlap ratio $(\%)$ & $0,50,100$ \\
Tilt angle (degree) & 3 \\
Penetration depth $(\mathrm{mm})$ & 2.2 \\
\hline
\end{tabular}

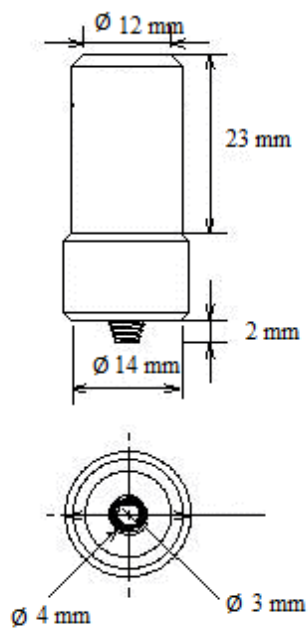

Figure 2. Welding tool for FSW (D2 Tool Steel - hardened to 62 HRC)

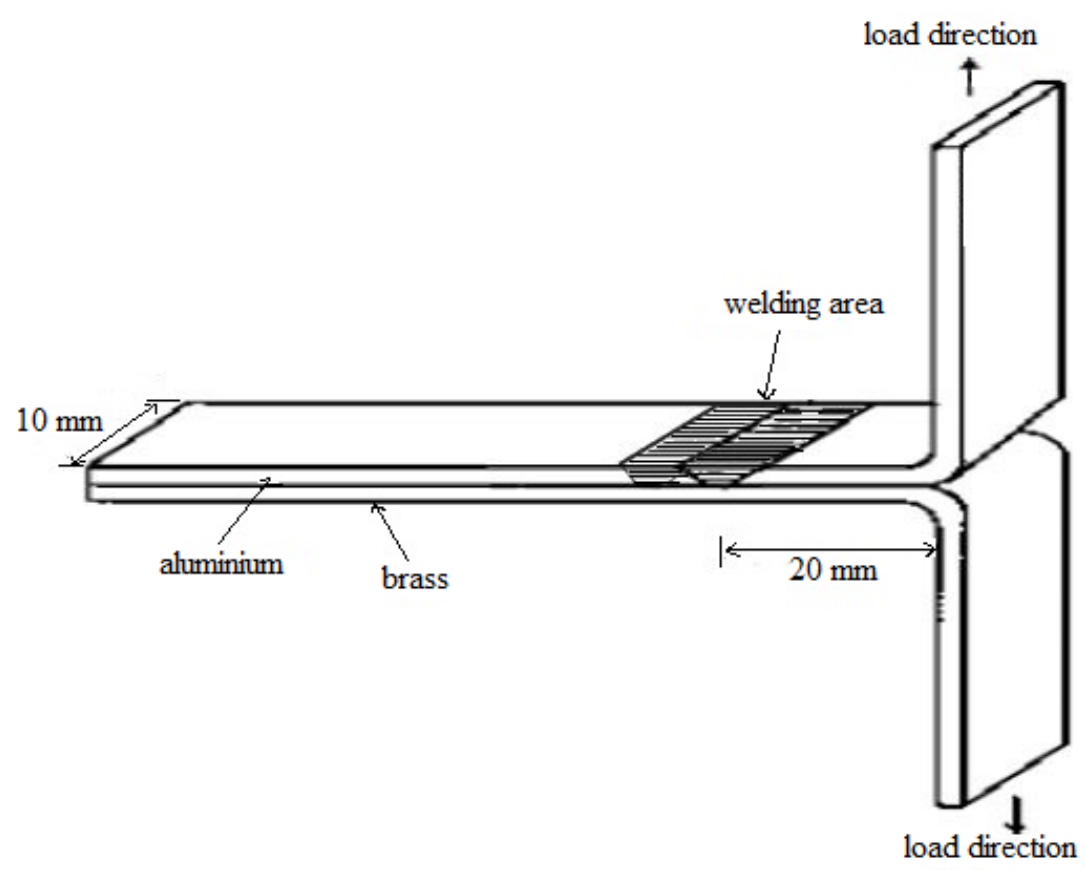

Figure 3. Schematic view of the specimen used for peel test. 


\section{RESULTS AND DISCUSSION}

In this study of continuous multi-seam friction stir process of $\mathrm{Al}-\mathrm{Cu}$ clad sheet, the effective shoulder diameter overlap ratio being considered is shown in Figure 1. Welding was carried out without a time gap between the subsequent passes and the penetration depth is constant at $2.2 \mathrm{~mm}$ for all passes. Figure 3 detailing the macrostructural appearance for all of the samples, where the $0 \%$ and $50 \%$ shoulder overlap samples are exhibiting excellent welding appearances on the surface while the $100 \%$ shoulder overlap sample showed some defects on the welding surface.

Shoulder overlap ratio
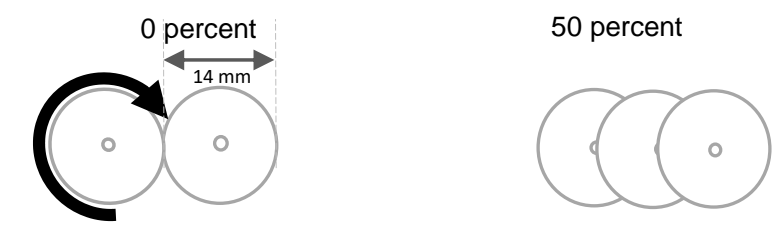
100 percent

Welded appearance
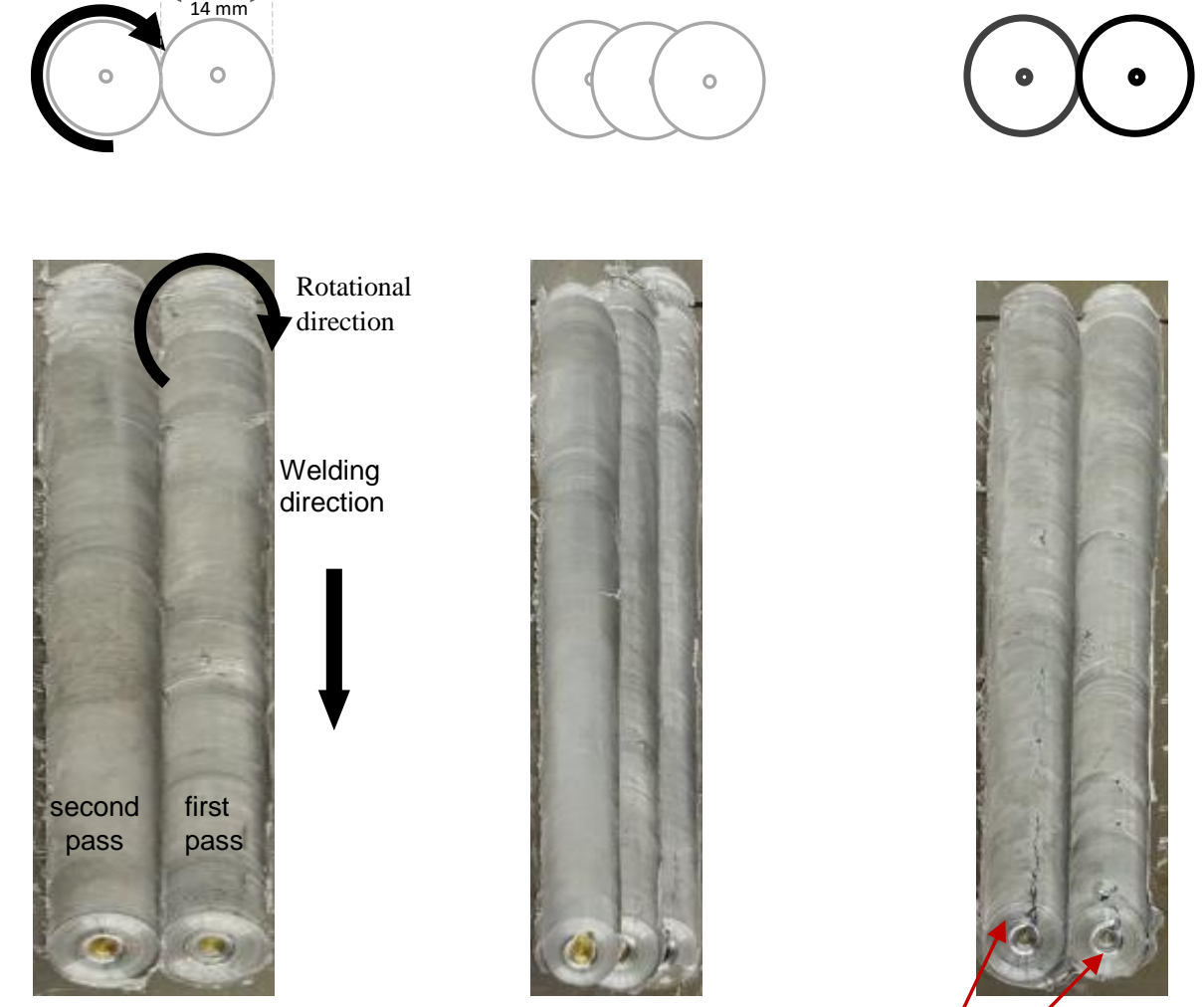

Cross-section macrostructure

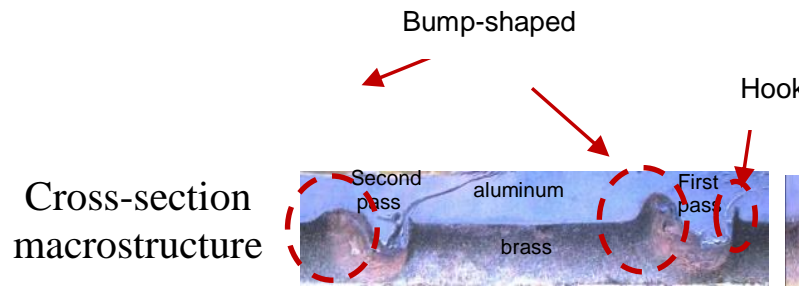

(a)

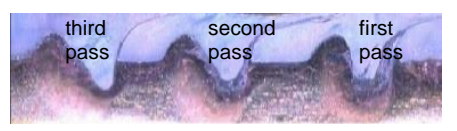

(b)

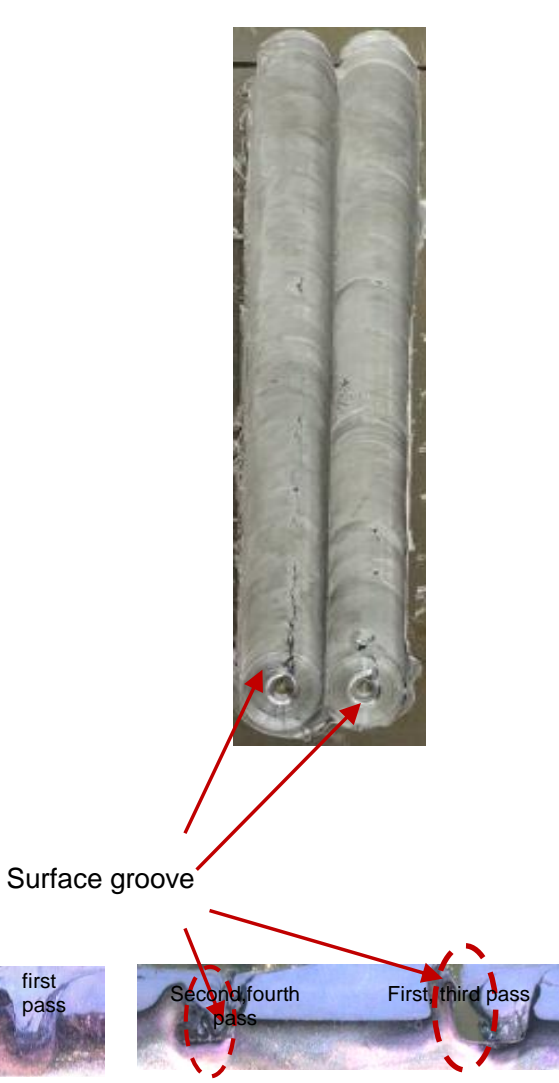

(c)

Figure 4. Macrostructure of the sample at (a) $0 \%$, (b) $50 \%$, (c) $100 \%$ shoulder overlaps at rotational speed $1055 \mathrm{rpm}$, transverse speed of $5.5 \mathrm{~mm} / \mathrm{min}$.

From Figure 4, the cross-section macrostructure illustrates bump-shaped with materials displaced at retreating side compared to advancing side and the larger stirred-whirl region at the brass area. Moreover, significant mixing of aluminium and brass was detected at the advancing side in the case of all of the samples. Furthermore, hook formed at advancing side due to upward flow on advancing site of stirred zone backside the tool 
drags the material upward and thus a fragment of the un-welded lap curves (hooks) up, forming an arc-shaped [20].

Figure 4 shows that the $100 \%$ shoulder overlap sample had surface groove defects on its welding surface and in the cross-sectional microstructural images. As the alloys are stirred, the aluminium sheet was plasticised and cascaded onto the brass bottom sheet due to the taper pin profile, which produced the pin influenced area. Due to the $100 \%$ shoulder overlap, the overlapping process increased the temperature of the area, which emulated the preheating effect of the previous pass. This pin-preheating occurrence increases liquidity while rearranges IMCs and grain coarsening, leading to the formation of grooves at the welding interfaces. This is consistent with Lakshminarayanan et al. [21], who reported weak bonds at the $100 \%$ shoulder lap sample of Al-Mg alloy.

It is also apparent from cross-section macrostructure in Figure 4 that a dark region is evident near the $\mathrm{Al}-\mathrm{Cu}$ interface. These regions are mainly formed at the joining interface and extend to the advance side (s) of the weld. The figure confirms that the dark region is present in every pass. Its formation could be due to the effect of turbulence stirring at high rotational speeds, which is consistent with the observation by Akbari and Beghnagh [7] and Saeid and Sazgari [16], where they reported a dark region made up of IMCs in the weld zone of the Al-Cu lap joints.

In Figure 5 and 6, the cross-section microstructural of the welds are shown. Meanwhile the TMAZs corresponding to the three welding passes almost visible in the aluminium part of the cross-section, but TMAZ/HAZ in the $\mathrm{Cu}$ side is clearly identified. Furthermore, in the Al TMAZ/HAZ, the microstructure is bigger than SZ region due to softening effect by shoulder overlapped. In SZ, a recrystallised fine-grained microstructure is produced from intense plastic deformation and frictional heat generation during the stirring process. The TMAZ is denoted by a highly deformed structure, laid on each side of the SZ. This region can be obtained from the dynamic recrystallisation process in the stirred zone and the base metal. Far from the weld is the HAZ zone, which experienced a thermal cycle but did not undergo any plastic deformation [7].

Figure 5 exhibits the microstructure of brass in multiple regions. Based on Figure 5 , the base metal's grain size in figure 5 (a) has an average grain size of $22 \mu \mathrm{m}$, with polygonal-shaped light $\alpha$-grains dispersed within the dark-region $\beta$-grains. Three distinct areas are noticeable; the SZ and TMAZ/HAZ, based on the pattern(s) of the grain. As can be observed in Figure 5 (b), the TMAZ was too small, due to the insufficient heat input or high thermal conductivity of the brass, thus dynamic recrystallization has not occurred, and hence the grains are just elongated along the shear stresses induced by the rotational tool [22]. The SZ for all passes reported the small grain size, which has an average grain size of fewer than $10 \mu \mathrm{m}$, according to Figure 5 and Figure 8 (a-c). The TMAZ/HAZ area shows the nearly equiaxed-shaped, with the notable exception being that the TMAZ/HAZ's average grain size is almost similar and bigger than the base metal, due to overaging effect during welding [17]. All three passes show a similar pattern of grains between the advancing/retreating sides, with the grains in SZ almost similar in grain size as Figure 5 (b) - (d). 

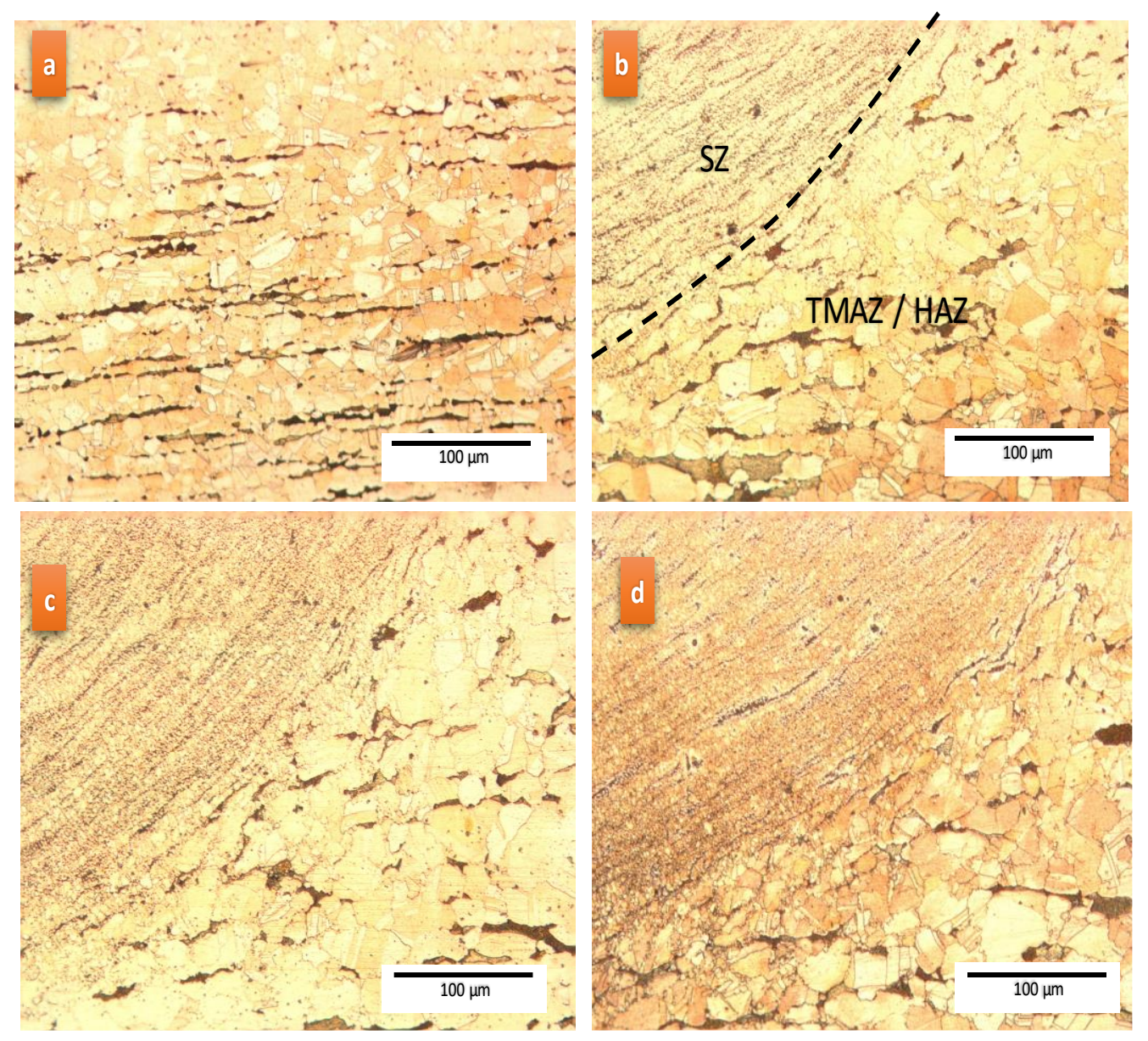

Figure 5. Microstructure of brass at 50\% shoulder overlap, (a) base metal- annealed, (b) SZ and TMAZ/HAZ for first pass (advancing side), (c) SZ and TMAZ/HAZ for second pass (advancing side) and (c) SZ and TMAZ/HAZ for third pass (advancing side).

The microstructure of the AA6061 aluminium alloy in the case of each pass is illustrated in Figure 6. In Figure 6 (a), it can be seen that the aluminium base metal (annealed) has a polygonal-shaped grain with average grain size is $7 \mu \mathrm{m}$. The SZ for all passes show almost similar grain size that have value below than $10 \mu \mathrm{m}$. The grain size across TMAZ/HAZ of Al as Figure 6 (b), (d), (f) and (h) show almost constant and lower than that of the Al-base metal, due to artificially aged precipitation hardenend aluminium alloy [17]. 

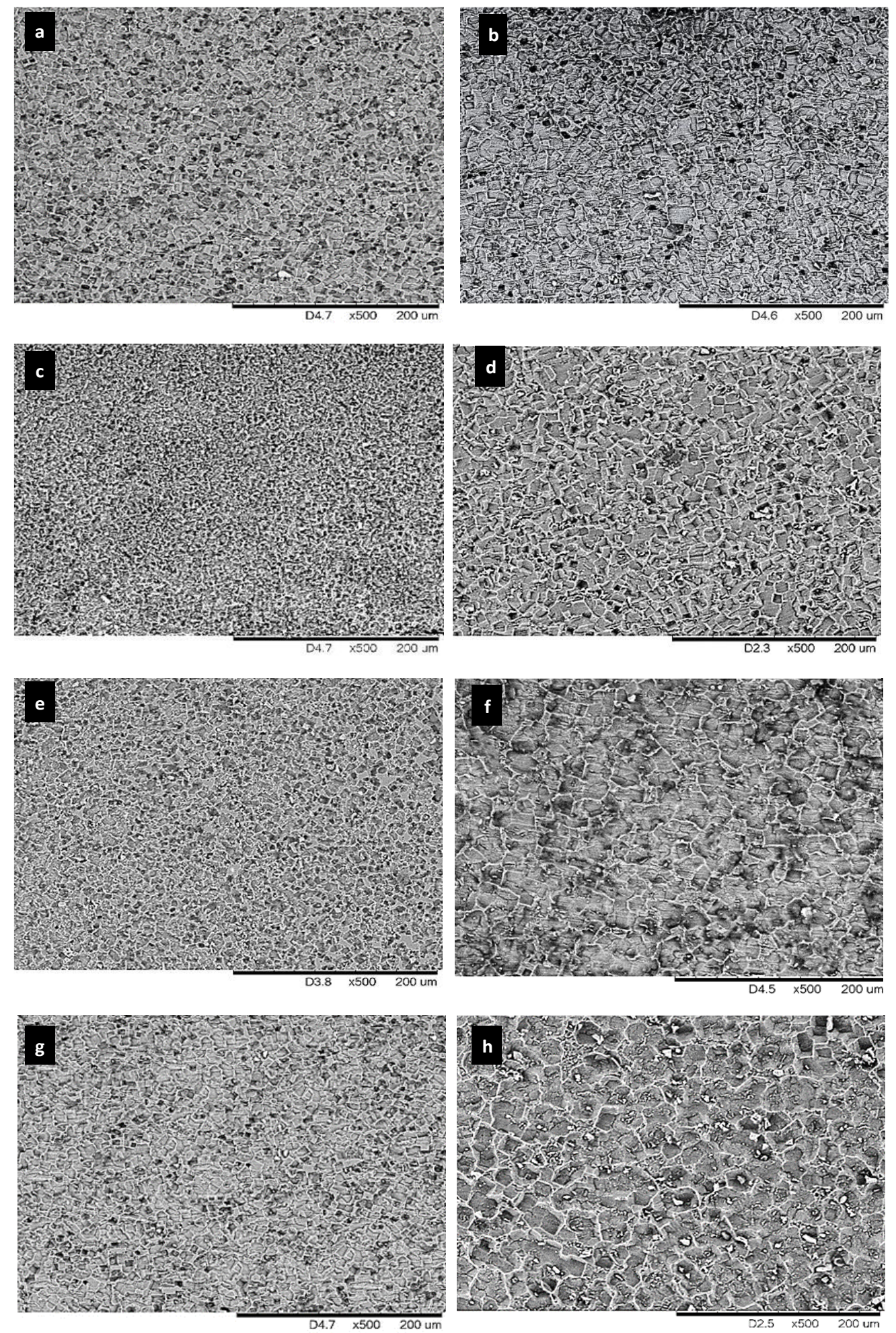

Figure 6. Microstructure of aluminium at 50\% shoulder overlap, (a) base metal- annealed, (b) TMAZ/HAZ for first pass (advancing side), (c) SZ for first pass, (d) TMAZ/HAZ between first and second pass, (e) SZ for second pass, (f) TMAZ/HAZ between second and third pass, (g) SZ for third pass and (h) TMAZ/HAZ for third pass (retreating side). 
Figure 7 depicts the XRD spectral regions at the Al-Cu interface. Referring to Figure 4, the IMCs are indicated by grey regions at the Al-brass interface. Esmaelli et al. [23] reported that the joining interface is the most suitable area for the formation of IMC due to the possibility of diffusion taking place in this area. The XRD analyses on this sample confirmed that the formed regions are made up of aluminium, brass, $\mathrm{Al}_{2} \mathrm{Cu}, \mathrm{Al}_{4} \mathrm{Cu}_{9}$, and $\mathrm{CuZn}$ phases. This finding agrees with the study by Akbari et al [7] that concluded the dissimilar friction lap joints of $5083 \mathrm{Al}$ plate to a brass produced $\mathrm{Al}_{2} \mathrm{Cu}, \mathrm{Al}_{4} \mathrm{Cu}$, and $\mathrm{CuZn}$ intermetallic compounds. The presence of $\mathrm{Al}_{2} \mathrm{Cu}$ and $\mathrm{Al}_{4} \mathrm{Cu}_{9}$ phases in the weld region indicates that a certain amount of stir took place at the interface, which entrapped some $\mathrm{Cu}$ in the stir zone due to the higher rotational speed [1]. Minimum amounts of the $\mathrm{CuZn}$ intermetallic compound was also detected.

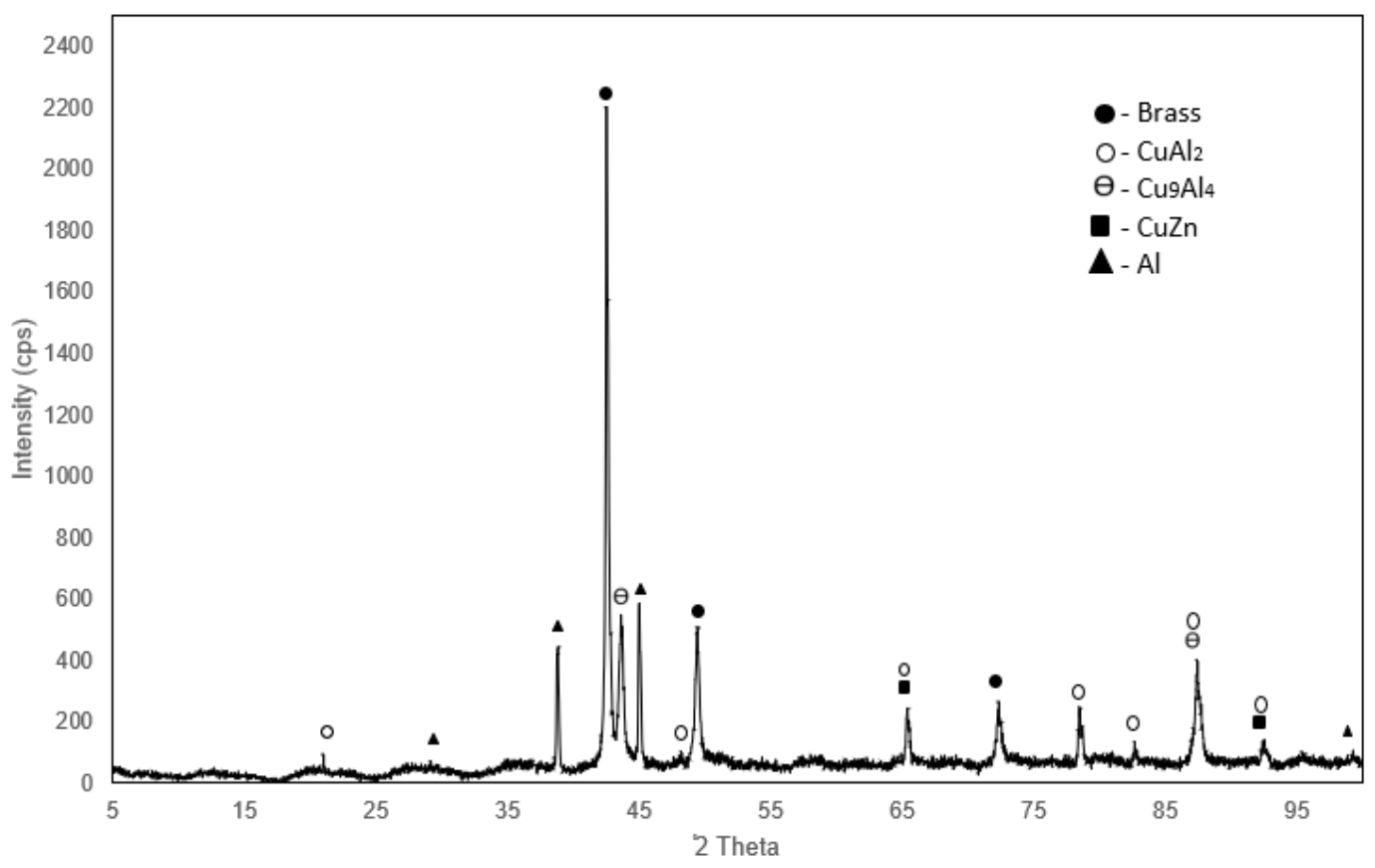

Figure 7. XRD result for sample at $50 \%$ shoulder overlap.

The Vickers microhardness results with average grain size measurements are shown in Figure 8 (a)-(c). The hardness measurement takes a line at mid-thickness the top $\mathrm{Al}$ and mid-thickness of the lower sheet (brass). It can be seen in Figure 8 (a), (b) and (c) for the sample with 0, 50 and 100\% overlap ratio that the maximum value of hardness for $\mathrm{Al}$ and brass were realized in the first pass SZ at the advancing site, where the IMCs formed. The increase of hardness in all SZ compared to base metal is caused by plastic deformation and dynamic recrystallisation at the same time during the welding process. It is related to the Hall-Petch effect [7], due to the rigorous plastic deformation that causes a reduction in hardness in grain size on top of the formation of hard IMCs within this region. The hardness across TMAZ/HAZ of $\mathrm{Al}$ is almost constant and lower than that of the Al-base metal (44 HV), due to artificially aged precipitation hardened aluminium alloy [11]. 


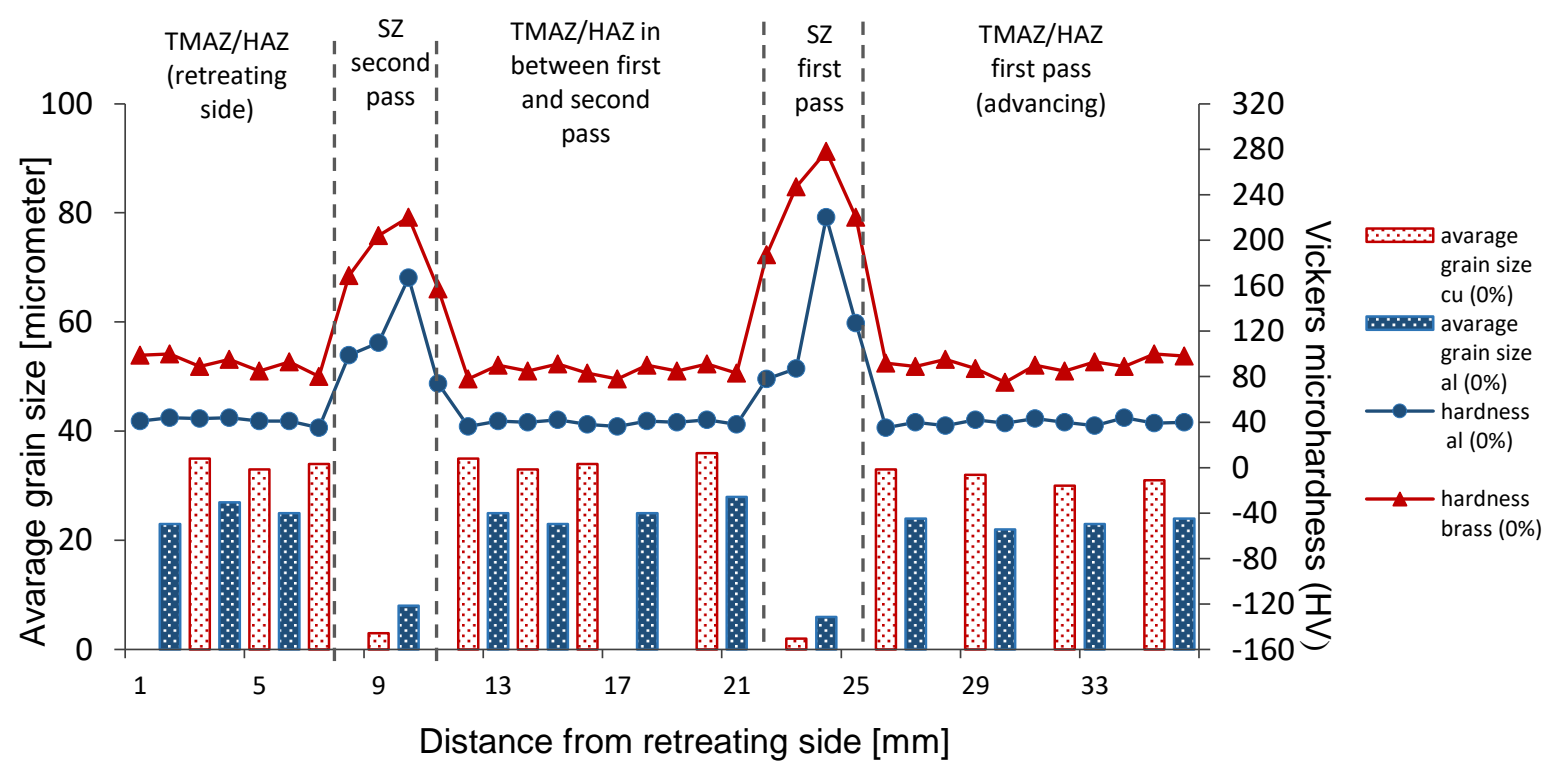

(a)

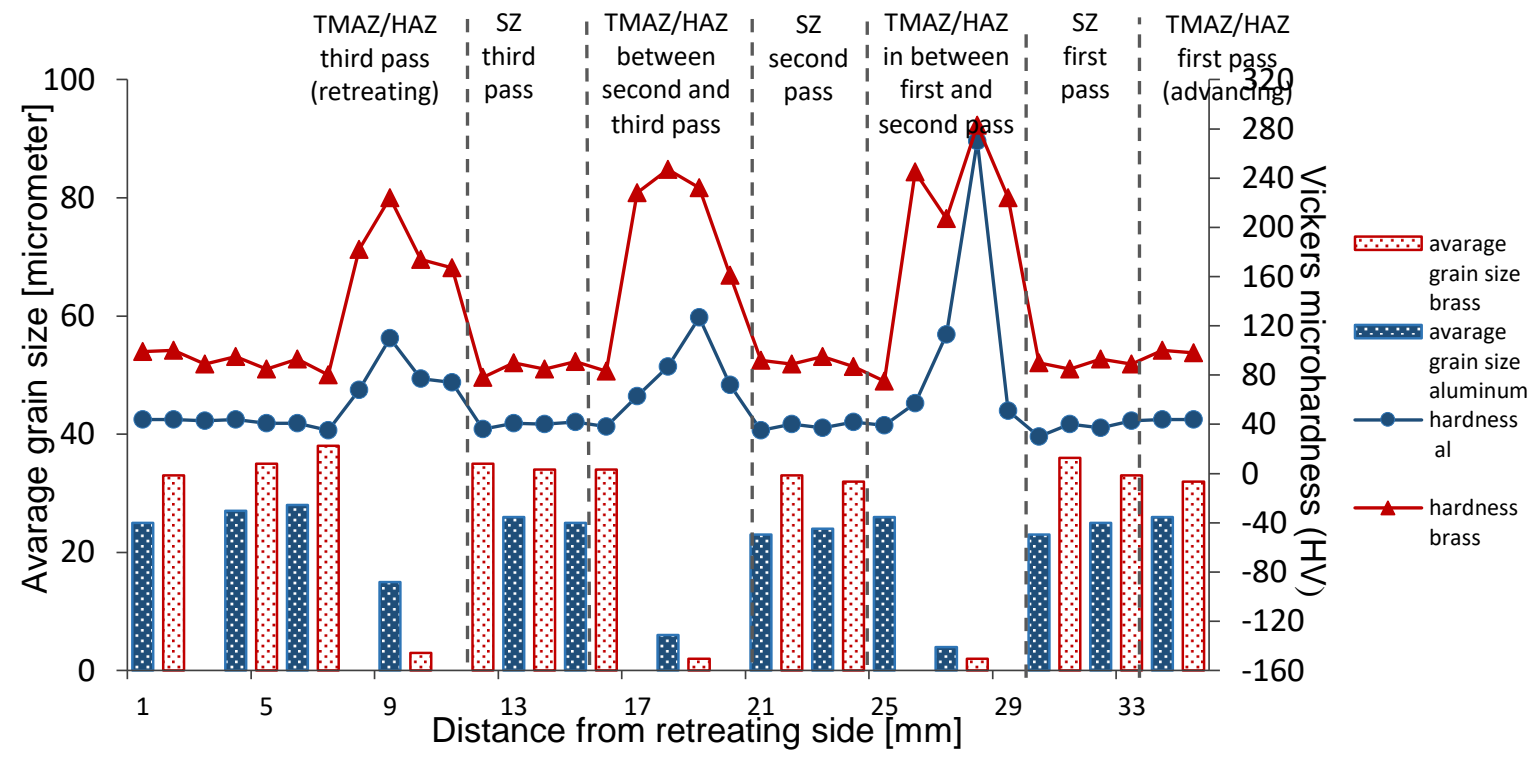

(b) 


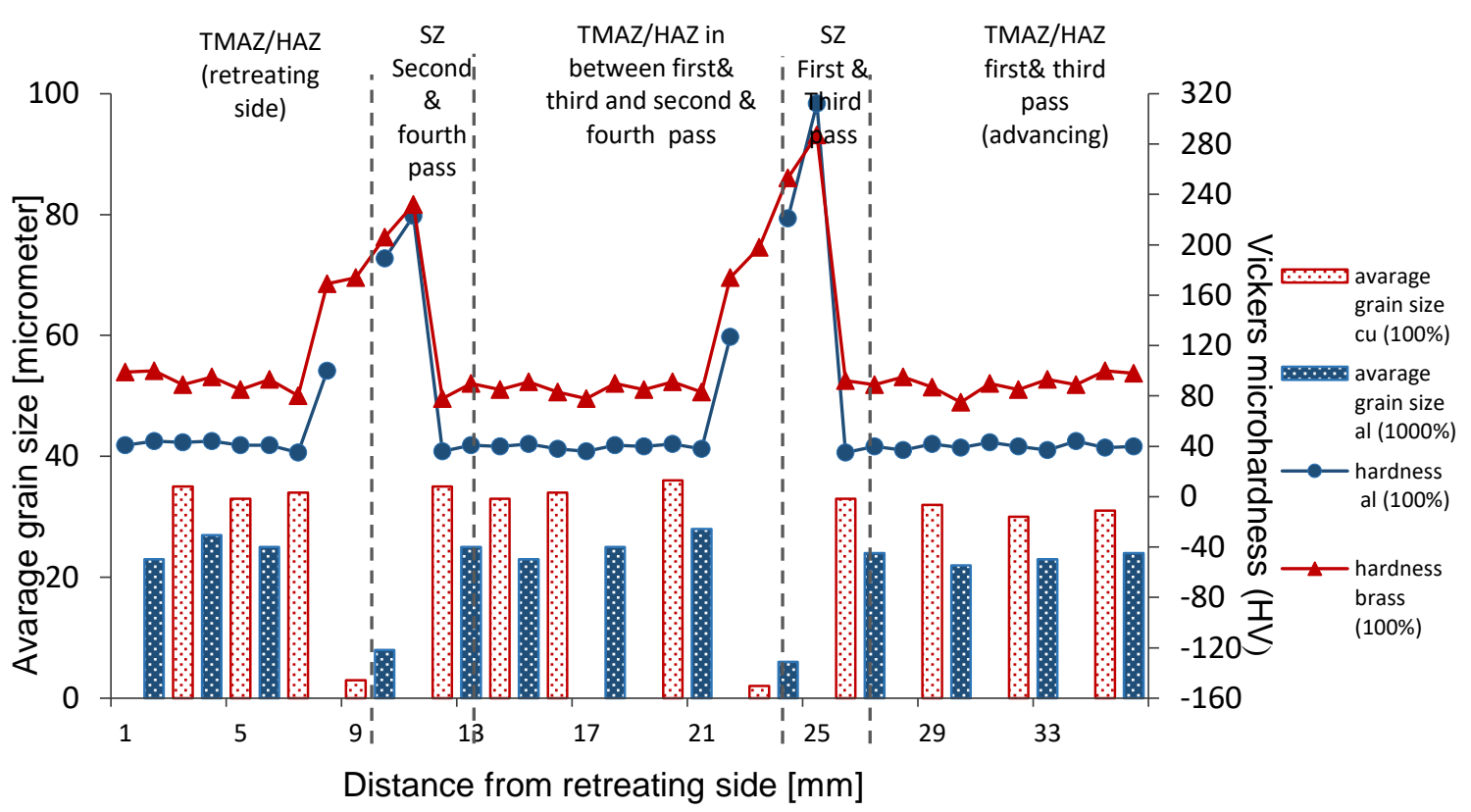

(c)

Figure 8. Vickers micro-hardness and average grain size of aluminium and brass at the cross-section of the; (a) $0 \%$ shoulder overlap, (b) $50 \%$ shoulder overlap, and (c) $100 \%$ shoulder overlap.

From Figure 8 (a)-(c), the hardness and grain size for all samples remained almost constant with some slight increase in grain size in SZ were contributed by IMCs formed at advancing side in SZ. This finding is agreeing with the study conducted by Sun et al. [24] that found similar grain size for various regions that have been performed overlapped with multiple passes. Johannes et al. [25] also reported that hardness and grain size remained approximately constant without variation between passes in FSW multi-pass of AA7075 alloy using a $42 \%$ overlapping between consecutive passes. Figure 8 (c) shows some discontinuity in hardness value in both $\mathrm{Al} \mathrm{SZ}$ due to grooves formed on the surface.

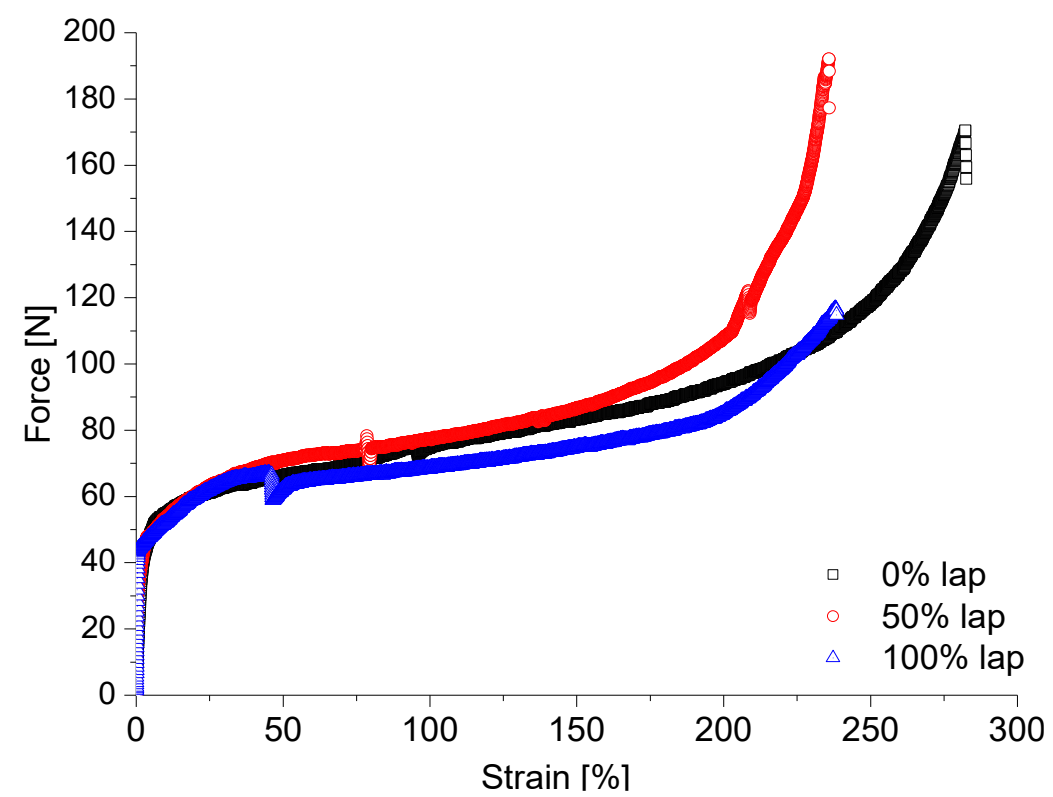

Figure 9. Peel test results for $0 \%, 50 \%$ and $100 \%$ overlap samples. 
The joining integrity was evaluated using peel strength, and the results are shown in

Figure 9 and Figure 10 respectively.

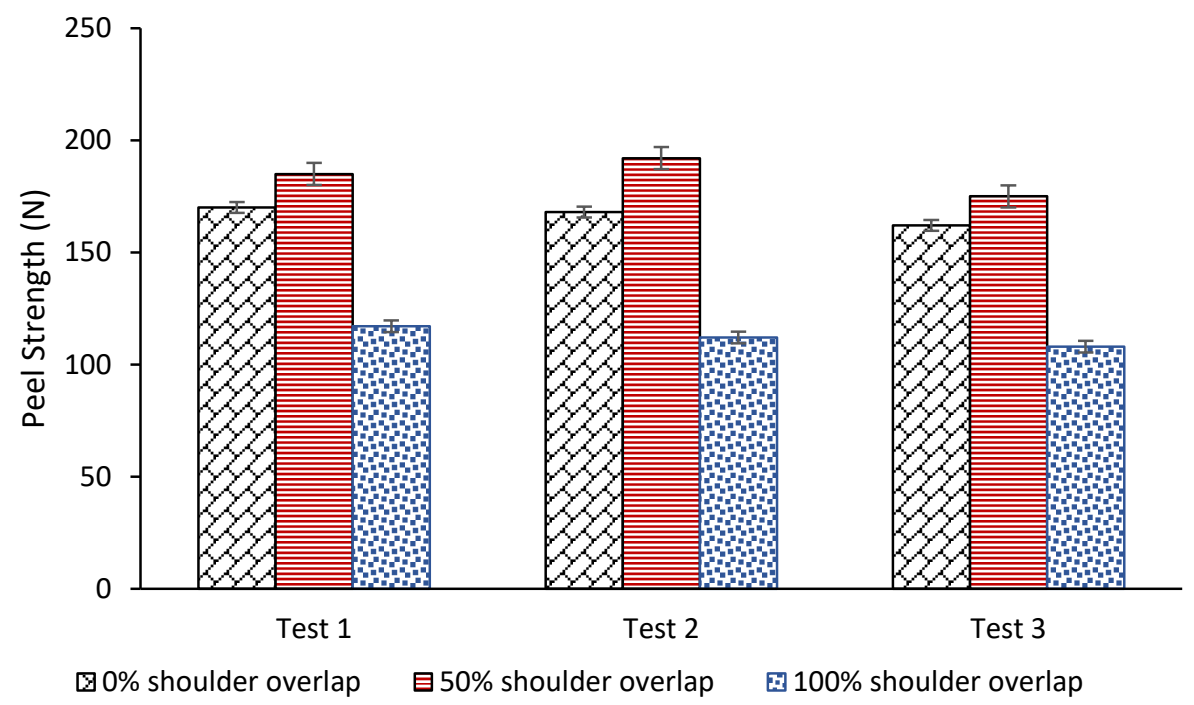

Figure 10. Peel test result

Figure 9 and 10, show that sample with 50\% overlap shows the highest peel strength with compared to sample 0 and $10 \%$ overlap. This high strength is contributed to friction stir diffusion caused by shoulder influenced heat generation that resulted in better $\mathrm{Al}-\mathrm{Cu}$ interface bonding. This shoulder influence region occurs when the tool pin was separated at a distance for two successive passes, the base material was already softened by the previous welding passes thermal cycles, which would have contributed for increasing the tool penetration under the constant axial load applied on the tool, promoting to a better weld quality [17]. For the sample with 0 and $100 \%$ of overlapped ratio show lower peel strength. Sample with $0 \%$ overlap ratio has too low overlap producing lower interface strength with compared to 50\% overlapped sample due to improper metallurgical bonding between the $\mathrm{Al}-\mathrm{Cu}$. In contrast, too adjacent overlap of $100 \%$ increases the peak temperature of the overlapping zone due to the preheating effect of previous pass, which can increase the possibility of grain coarsening, liquation and rearrangement of IMCs [21]. This results in the formation of surface grooves that cause weaker bonding at the $\mathrm{Al} / \mathrm{Cu}$ interfaces. The peel test discovered that fracture initiated from the triple junction (hook) among $\mathrm{Al}, \mathrm{Cu}$ and SZ, propagating easily through the IMCs on the advancing side before cutting through the thickness of the bulk SZ.

\section{CONCLUSIONS}

1) All the grains in the stirred zone for both alloys are equiaxed-shaped, and its sizes smaller than that of the HAZ/TMAZ region nearby. The shape of grain in the TMAZ/HAZ is similar to its base metal, except that it's slightly larger.

2) The XRD results confirmed that the multi-spectrum in samples contain aluminium, brass, and some IMCs; $\mathrm{Al}_{2} \mathrm{Cu}, \mathrm{Al}_{4} \mathrm{Cu}_{9}$, and $\mathrm{CuZn}$ phases.

3) The increase of hardness in the stirred zone was the result of the Hall-Petch effects from the intense plastic deformation, in addition to the formation of hard IMCs in this region. 
4) Friction stir claded Al-brass composite plate at $100 \%$ shoulder overlap sample exhibited groove defect produced by the pin overlapped effect. Samples with $50 \%$ shoulder overlap reported the highest peel strength due to softening by shoulder influenced region that makes greater tool penetration, producing better weld quality. Sample with 0\% overlap ratio has too low overlapped produced lower interface strength due to improper metallurgical bonding between the $\mathrm{Al}-\mathrm{Cu}$ with compared to $50 \%$ overlapped sample.

\section{ACKNOWLEDGEMENT}

The authors would like to thank Universiti Kebangsaan Malaysia for their financial support under the research grant DIP-2014-024.

\section{REFERENCES}

[1] Ouyang J, Yarrapareddy E, Kovacevic R. Microstructural evolution in the friction stir welded 6061 aluminum alloy (T6-temper condition) to copper. J Mater Process Technol 2006;172:110-22.

[2] Al-Roubaiy AO, Nabat SM, Batako ADL. Experimental and theoretical analysis of friction stir welding of Al-Cu joints. Int J Adv Manuf Technol 2014;71:163142.

[3] Fotoohi Y, Rasaee S, Bisadi H, Zahedi M. Effect of friction stir welding parameters on the mechanical properties and microstructure of the dissimilar Al5083-copper butt joint. Proc Inst Mech Eng Part L J Mater Des Appl 2014;228:334-40.

[4] Weigl M, Albert F, Schmidt M. Enhancing the ductility of laser-welde copperaluminum connections by using adapted filler materia. Phys Procedia 2011;12:335-41.

[5] Bergmann JP, Petzoldt F, Schurer R, Schneider S. Solid-state welding of aluminum to copper - Case studies. Weld World 2013;57:541-50.

[6] Hasan MM, Ishak M, Rejab MRM. A simplified design of clamping system and fixtures for friction stir welding of aluminium alloys. J Mech Eng Sci 2015;9:1628-39.

[7] Akbari M, Behnagh RA. Dissimilar friction-stir lap joining of 5083 aluminum alloy to CuZn34 brass. Metall Mater Trans B Process Metall Mater Process Sci 2012;43:1177-86.

[8] Xue P, Ni DR, Wang D, Xiao BL, Ma ZY. Effect of friction stir welding parameters on the microstructure and mechanical properties of the dissimilar Al$\mathrm{Cu}$ joints. Mater Sci Eng A 2011;528:4683-9.

[9] Carlone P, Astarita A, Palazzo GS, Paradiso V, Squillace A. Microstructural aspects in $\mathrm{Al}-\mathrm{Cu}$ dissimilar joining by FSW. Int $\mathrm{J}$ Adv Manuf Technol 2015;79:1109-16.

[10] Abbasi M, Karimi Taheri a., Salehi MT. Growth rate of intermetallic compounds in $\mathrm{Al} / \mathrm{Cu}$ bimetal produced by cold roll welding process. J Alloys Compd 2001;319:233-41.

[11] Mishra RS, Ma ZY. Friction stir welding and processing 2005;50:1-78.

[12] Leitão C, Leal RM, Rodrigues DM, Vilaça P, Loureiro A. Material flow in friction 
stir welding. Microsc Microanal 2008;14:87-90.

[13] Brown R, Tang W, Reynolds AP. Multi-pass friction stir welding in alloy 7050T7451: Effects on weld response variables and on weld properties. Mater Sci Eng A 2009;513-514:115-21.

[14] Al-Fadhalah KJ, Almazrouee AI, Aloraier AS. Microstructure and mechanical properties of multi-pass friction stir processed aluminum alloy 6063. Mater Des 2014;53:550-60.

[15] Lakhsminarayanan AK, Annamalai VE. Fabrication and performance evaluation of dissimilar magnesium-aluminium alloy multi-seam friction stir clad joints. Trans Nonferrous Met Soc China (English Ed 2017;27:25-35.

[16] Leal RM, Loureiro A. Effect of overlapping friction stir welding passes in the quality of welds of aluminium alloys. Mater Des 2008;29:982-91.

[17] Leitao C, Arruti E, Aldanondo E, Rodrigues DM. Aluminium-steel lap joining by multipass friction stir welding. Mater Des 2016;106:153-60.

[18] Saeid T, Sazgari B. Microstructural and mechanical properties of friction stir welded aluminum / copper lap joints 2008;460:535-8.

[19] matweb. MatWeb: Online Materials Information Resource. Internet 2010.

[20] Shubhavardhan RN, Rahman MM. Effect of FSW Parameters on Hook formation , Microstructure and Fracture Strength of Al , Mg alloys 2017;5:1730-6.

[21] Lakshminarayanan AK, Annamalai V. E. Fabrication and performance evaluation of dissimilar magnesium-aluminium alloy multi-seam friction stir clad joints. Trans Nonferrous Met Soc China (English Ed 2017;27:25-35.

[22] Heidarzadeh A, Laleh HM, Gerami H, Hosseinpour P, Shabestari MJ, Bahari R. The origin of different microstructural and strengthening mechanisms of copper and brass in their dissimilar friction stir welded joint. Mater Sci Eng A 2018;735:336-42.

[23] Esmaeili A, Zareie Rajani HR, Sharbati M, Givi MKB, Shamanian M. The role of rotation speed on intermetallic compounds formation and mechanical behavior of friction stir welded brass/aluminum 1050 couple. Intermetallics 2011;19:1711-9.

[24] Sun YF, Fujii H, Takaki N, Okitsu Y. Microstructure and mechanical properties of dissimilar Al alloy/steel joints prepared by a flat spot friction stir welding technique. Mater Des 2013;47:350-7.

[25] Johannes LB, Mishra RS. Multiple passes of friction stir processing for the creation of superplastic 7075 aluminum. Mater Sci Eng A 2007;464:255-60. 